\title{
Journal of Mind and Medical Sciences
}

\section{Intestinal dysbiosis - a new treatment target in the prevention of colorectal cancer}

Florinela-Andrada Dumitru

EMERGENCY HOSPITAL OF CONSTANTA, DEPARTMENT OF GASTROENTEROLOGY, CONSTANTA,

ROMANIA, d.andrada92@gmail.com

Sergiu loan Micu

EMERGENCY HOSPITAL OF CONSTANTA, DEPARTMENT OF GASTROENTEROLOGY, CONSTANTA, ROMANIA

Roxana Emanuela Popoiag

OVIDIUS UNIVERSITY, FACULTY OF MEDICINE, CONSTANTA, ROMANIA

Marilena Musat

EMERGENCY HOSPITAL OF CONSTANTA, DEPARTMENT OF GASTROENTEROLOGY, CONSTANTA, RGMPANAhis and additional works at: https://scholar.valpo.edu/jmms

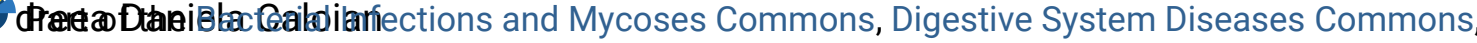

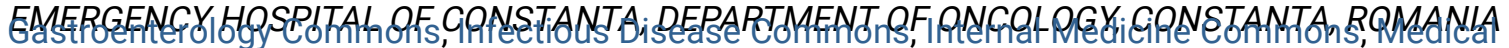

Microbiology Commons, Medical Nutrition Commons, Neoplasms Commons, Oncology Commons, and the Surgepvegefornadaritional authors

\section{Recommended Citation}

Dumitru, Florinela-Andrada; Micu, Sergiu Ioan; Popoiag, Roxana Emanuela; Musat, Marilena; Caloian, Andreea Daniela; Calu, Valentin; Constantin, Vlad Denis; Balan, Daniela Gabriela; Nitipir, Cornelia; and Enache, Florin (2021) "Intestinal dysbiosis - a new treatment target in the prevention of colorectal cancer," Journal of Mind and Medical Sciences: Vol. 8 : Iss. 2 , Article 8.

DOI: $10.22543 / 7674.82 . P 221228$

Available at: https://scholar.valpo.edu/jmms/vol8/iss2/8

This Review Article is brought to you for free and open access by ValpoScholar. It has been accepted for inclusion in Journal of Mind and Medical Sciences by an authorized administrator of ValpoScholar. For more information, please contact a ValpoScholar staff member at scholar@valpo.edu. 


\section{Intestinal dysbiosis - a new treatment target in the prevention of colorectal}

cancer

\section{Authors}

Florinela-Andrada Dumitru, Sergiu Ioan Micu, Roxana Emanuela Popoiag, Marilena Musat, Andreea Daniela Caloian, Valentin Calu, Vlad Denis Constantin, Daniela Gabriela Balan, Cornelia Nitipir, and Florin Enache 


\title{
Intestinal dysbiosis - a new treatment target in the prevention of colorectal cancer
}

\author{
Gabriela Balan ${ }^{5}$, Cornelia Nitipir ${ }^{6}$, Florin Enache ${ }^{7}$

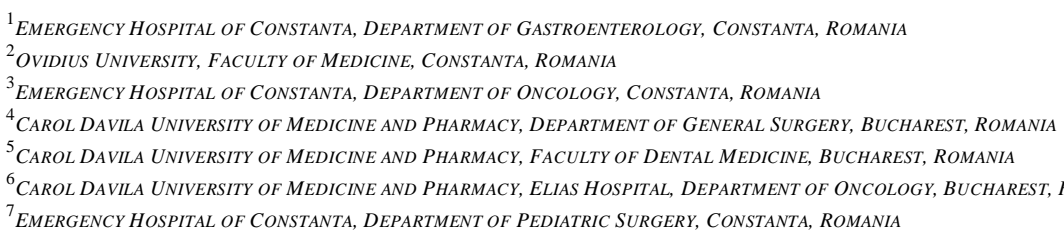

Florinela-Andrada Dumitru ${ }^{1}$, Sergiu Ioan Micu ${ }^{1}$, Roxana Emanuela Popoiag ${ }^{2}$, Marilena Musat $^{1}$, Andreea Daniela Caloian ${ }^{3}$, Valentin Calu ${ }^{4}$, Vlad Denis Constantin ${ }^{4}$, Daniela

\section{ABSTRACT}

The gastrointestinal microbiome contains at least 100 trillion microorganisms (bacteria, viruses, fungi), whose distribution varies from the mouth to the rectum spatially and temporally throughout one's lifetime. The microbiome benefits from advancing research due to its major role in human health. Studies indicate that its functions are immunity, metabolic processes and mucosal barrier. The disturbances of these functions, dysbiosis, influence physiology, lead to diabetes, inflammatory bowel disease, obesity and colon tumorigenesis. The third most common form of cancer, colorectal cancer, is the result of many factors and genes, and although the link between dysbiosis and this type of cancer is poorly characterized, it has been shown that some bacterial species and their metabolites have a critical role in developing colorectal cancer. Also, gut microbiota plays a role in the inflammatory response and immune process perturbations during the progression of colorectal cancer. Some new technologies, such as metagenome sequencing, facilitated the progress by analyzing the metabolic and genetic profile of microbiota, revealing details about the bacterial composition, host interactions, and taxonomic alterations. This review summarizes the studies regarding the link between gut microbiota and colorectal cancer, targeting new therapeutic strategies.

\section{Introduction}

Dysbiosis or the alteration of the gut microbiome's composition has recently been associated with various human diseases, including even cancer [1]. A possible mechanism through which the microbiota could influence carcinogenesis is the biosynthesis of chemical carcinogens such as N-nitroso compounds or acetaldehyde by microbes, associated with dysbiosis-related inflammation [2]. It was estimated that more than $70 \%$ of the human microbiome is located in the colon, so this part of the digestive tract is considered to be its most heavily colonized section [3]. It may be the reason why the colon is more prone to developing cancer, in contrast with the small intestine (the cancer incidence is 12 -fold higher in the colon compared to the small intestine) [4]. It is important to know that the lifestyle and the dietary habits corroborated with other risk factors including advanced age, impaired glucose metabolism, pro-inflammatory states, previous therapies such as antibiotic therapy, chemotherapy, co-morbidities modulate the gut microbiota; that is maybe why the microenvironment created by the alterations of the typical resident colonic flora could be more favorable to tumor development at this level [5-8]. Many studies report specific alterations in the gut microbiome associated with colorectal cancer; that is why it was taken into consideration as a screening method, being very important in the early diagnosis (early diagnosed patients with colorectal cancer (stages 0 , I or II), have $80 \%$ survival rates over five years in contrast with the ones diagnosed in stage 
IV that have only a $10 \%$ survival rate). Therefore, a promising strategy for the early diagnosis of colorectal cancer is the detection of specific microbiome alterations [9-13].

\section{Discussions}

\section{Human microbiota}

\subsection{Microbial species}

The human body is colonized by a complex of the symbiotic, commensal and pathogenic microbial community. The human microbiome does not only include bacteria, but also fungi, protozoa and viruses [14,15]. A comprehensive group of living organisms considered a domain of life themselves are bacteria, many major bacterial phyla compose the human microbiota. Among them, the majority can be assigned to four types: Firmicutes, Bacteroidetes, Actinobacteria and Proteobacteria [16]. Firmicutes and Bacteroidetes represent more than $90 \%$ of the gut microbiome [17]. Firmicutes are composed mainly of Clostridia (Grampositive and anaerobic) and Bacilli (obligate or facultative aerobics) [18,19]. Actinobacteria (for example, Bifidobacterium) are multiple branching rods, Grampositive, non-spore-forming, non-motile and anaerobic bacteria. The phylum Bacteroidetes is composed of nonspore, Gram-negative bacteria. Proteobacteria (for instance, Escherichia, Klebsiella, Enterobacter) are aerobic or facultative anaerobic, non-spore-forming rod, Gramnegative bacteria [20].

There is a concept called "enterotype clusters", through which the microbiota structure and different microbial colonization are better defined in various cohorts. It also allows the classification of each person by the relative abundance of specific bacterial in the fecal samples. The results of the studies performed on Japanese, American and European subjects confirm three clusters dominated by Bacteroides (enterotype 1), Prevotella (enterotype 2) and Ruminococcus (enterotype 3); each one of these three types is characterized by the relative abundance of metabolic pathways and by specific taxonomic composition [21].

\subsection{Inflammatory and immune responses}

The microbiota composition varies according to the various locations along the gastrointestinal tract. Microbial dysbiosis can be the result of the dysregulation of the intestinal immune system.

There is a delicate balance between the immune system and immune-regulatory functions, because the loss of a specific species can suppress the innate immune system or an overreaction. There is an immunological and physical barrier in the intestinal mucosa, between the luminal bacteria and the underlying immune cells, called intestinal epithelial cells; hematopoietic cells and intestinal epithelial cells generate various receptors named pattern recognition receptors; these mediate the interactions between the commensal microbiota and the immune system [22]. Tolllike receptors and nuclear oligomerization domain-like represent some pattern recognition receptors; these recognize microbial molecules (microbe-associated molecular patterns - lipid A, lipopolysaccharides, flagella, peptidoglycans and microbial RNA/DNA) and activate inflammasomes such as TNF alpha, cytokines and IL-1 beta [23].

It is essential to understand how and when dysbiosis and the genetic defects in the mucosa-intestinal epithelial cells and innate regulatory mechanisms can lead to the development of inflammatory or infectious diseases [24].

\subsection{The metabolic role}

Recent studies have revealed that the gut microbiota can generate genotoxic or metabolite stress in the intestinal environment and thus, genetic and epigenetic changes are facilitated and lead to cancer. As to provide the repair of DNA damage and energy for multidrug resistance efflux pumps, glycolysis will generate adenosine triphosphate and nicotinamide adenine dinucleotide for the polymerase. That is why enhanced glycolysis can have an impact on drug resistance. Glucose metabolism can be improved by dietary fiber that increases the abundance of Prevotella. An increased amount of Prevotella in the gut microbiota protects against Bacteroides induced glucose intolerance. The last one may facilitate drug resistance and also could affect the tumor growth. Increased glycolysis enables the diversion of glycolytic metabolites into other important biosynthetic pathways that play an essential role in cell proliferation. That is why the control of gut microbiota and their metabolites can be a useful strategy in reducing drug resistance [25,26].

It has been shown that chronic low-grade inflammation, promoted by lipopolysaccharides, is linked to the occurrence of insulin resistance and obesity. These endotoxins may cross the gut mucosa by infiltrating chylomicrons or weak intestinal junctions, stimulating the absorption of cholesterol and dietary triglycerides from the gut to the plasma, producing a natural immune response. Compared to healthy individuals, the level of circulating endotoxins was $20 \%$ higher in people with glucose intolerance or obesity, and $125 \%$ higher in type 2 diabetes individuals. These elevated levels were also correlated with high concentrations of TNF- $\alpha$ and IL-6 in adipocytes. Also, a diet poor in fruit and fiber, but rich in highcarbohydrates or high-fat, triggers the systemic secretion of lipopolysaccharides, the expression of Toll-like receptor 4 , nuclear factor $\kappa \mathrm{B}$ and the suppression of cytokines. These factors regulate the pathways involved in insulin secretion [27-30].

The microbiota plays an important role in many aspects of the metabolism and brain functions. Several studies reveal the importance of microbiota and micronutrients in 
attention deficit hyperactivity disorder in children. Actinobacteria abundance may have a role in neuropsychiatric disorders, while Bifidobacterium spp are considered to have a protective role by several studies, while in other studies, they seem to be key-driver [31-33]. Regarding the micronutrients, increased Copper and Copper/zinc ratio are associated with attention deficit. Dysbiosis and the destruction of the intestinal barrier function was found to be a risk factor for the occurrence and worsening of the chronic kidney disease. The mechanisms involved are chronic inflammation and increased productions of uremic toxins [34-37].

\subsection{DNA damage}

The accumulation of DNA deteriorations destabilizes the human genome, promoting aberrant cells (pre - / cancerous) to preserve or to accelerate mutations. Gut microorganisms may be a serious source of DNA mutagens. For instance, studies have proven that some Enterococcus spp provide reactive oxygen species, such as hydroxyl free radicals, that cause DNA alterations, point mutations, protein-DNA crosslinking, destabilizing colorectal cancer-related genes. Enterotoxigenic Bacteroides fragilis triggers spermine oxidase expression on colonic epithelial cells, promoting DNA deteriorations. Furthermore, PKS-positive Escherichia Coli stimulates DNA double-strand breaks, cell cycle arrest and aneuploidy cell division. All these findings prove that microorganisms may induce DNA alterations and destabilize the genome directly or indirectly. Thus, the gut microbiome may be a risk factor and a treatment objective in colorectal cancer [38].

\subsection{The modulation of cell proliferation}

To control the cell function and structure in normal tissues, there are signals that control the cell's growth and death. When perturbations of apoptotic signals and cell proliferation develop, they will promote continued cell proliferation, thus forming malignant tumors. Enterotoxigenic Bacteroides fragilis drop Bacteroides fragilis toxin (fragilysin) to promote E-cadherin cleavage, promoting beta-catenin nuclear translocation, transcriptional upregulation of the proto-oncogene c-Myc, and colonic cell proliferation. Identically, fusobacterium nucleatum connects to E-cadherin through FadA, triggering downstream pathways and promoting cell proliferation. In conclusion, studies have proven that dysbiosis is a cause of aberrant epithelial cell proliferation and early tumor development [37].

\section{Gut microbiota and colorectal cancer - is there any link?}

Colorectal cancer is the fourth most frequent type of cancer worldwide, with a total of $8.5 \%$ of all new cases of cancer/ year, thus being a major health problem [39]. The development of this complex malignant disorder contributes to a large amount of factors, including environmental risk and genetic factors [40]. Considering that less than $20 \%$ of the cases are hereditary, we can conclude that environmental risk factors play a decisive role, including alcohol consumption, smoking, diabetes, obesity, a diet rich in animal fat, processed foods, red meat, low intake of fruits and fibers [31,40]. Studies show that genetic and epigenetic alterations in proto-oncogenes, tumor suppressor genes and DNA repair genes, contribute to the tumor transformation of the normal colonic epithelium. Recently, studies have focused on gut microbiota examination, and reported alterations in colorectal cancer samples, indicating that the microbiome may be a crucial factor in the induction and evolution of colorectal cancer [41-43].

The gut microbiota contributes to the epithelial barrier function and mucosal homeostasis, efficiently keeping bacteria into the lumen. These function perturbations promote an increased intestinal permeability, which is correlated with many gastrointestinal diseases, such as irritable bowel syndrome, celiac disease, inflammatory bowel disease, and colorectal development. The gut microbiota metabolic products may also influence the immune response, activating pro-inflammatory mediators, such as interleukin-6, cytokines, and tumor necrosis factor $-\alpha$, leading to epithelial cell damage [44]. Furthermore, bacterial species can cause inflammatory responses or produce toxins, thus damaging the epithelial cells directly. Examples: species of Bacteroides fragilis and Enterococcus faecalis generate enterotoxins and reactive oxygen inducing oxidative DNA damage; Bacteroides fragilis induces cellular proliferation by activating $\beta$ catenin nuclear signaling; Fusobacterium nucleatum adheres and invades epithelial cells by the FadA surface protein $[45,46]$.

Studies have shown that plenty of these bacterial species are found in different amounts in healthy individuals compared to colorectal cancer samples. Thus, microbiota in colorectal patients contains especially proinflammatory opportunistic microorganisms and pathogens associated with metabolic disorders, and a reduced amount of butyrate-producing bacteria, which has a significant role in intestinal homeostasis [47]. Moreover, some bacterial species have a high prevalence in colorectal patients than healthy populations: Escherichia coli, Bacteroides fragilis, Enterococcus faecalis, Streptococcus gallolyticus, Fusobacterium nucleatum. Instead, types of bacteria such as Roseburia, Clostridium, Faecalibacerium and Bifidobacterium are reduced [48]. Studies focused on discovering oncobacteria, but no single species have been universally detected in all colorectal patients. This indicates that various associations of microorganisms may 
act synergistically, and the modifications in both damaging or protective bacterial populations may be responsible for the development and evolution of colorectal cancer [49].

\section{Microbiome - a tool in the early diagnosis of colorectal} cancer?

The development of colorectal cancer from normal mucosa is a complex multi-step process, from preneoplastic lesions to adenomatous polyps to carcinoma proliferation, which may take about ten years to occur. This is the main reason why colorectal cancer is a malignancy that may be screened. Many countries have initiated population screening and prevention programs, using fecal occult blood test and the fecal immunochemical test, followed by colonoscopy when the tests are positive. Thus, precancerous proliferation may be detected, with a highly successful treatment, preventing colorectal cancer and improving the overall survival $[50,51]$.

Current studies have focused on additional criteria that may be considered in the algorithms used to lead patients to colonoscopy, including molecular biomarkers connected to the processes of carcinogenesis, such as circulating tumor cells and cell-free DNA microRNAs, and metabolites from plasma samples [52].

As discussed above, microbiome alterations are associated with colorectal cancer, so the option of using different microbiome stool signatures has emerged. Even though there is no major difference in the overall composition of microbiota in colorectal patients and healthy individuals, the distinction involves plenty of key microorganisms. This is one of the reasons why colorectal cancer diagnosis needs to develop some specific tests for those suggestive species, without evaluating the whole microbiome. For example, Fusobacterium nucleatum has been persistently discovered in large amounts in the feces of patients with adenoma and colorectal cancer, compared to healthy humans and cancer tissue compared to circumferential normal tissue [53].

Even though efforts have been conducted to discover the bacterial biomarkers that may predict the risk of colorectal cancer, major factors such as genetics, lifestyle, and environmental factors are known to influence the composition of gut microbiota. Also, the quality of samples, experimental protocols, and bioinformatics tools are all influencing factors and may explain the differences between studies [54]. Regardless of the advances in bacterial signatures in colorectal cancer patients, the clinical routine is still not using microbiome biomarkers in the screening of colorectal cancer.

In conclusion, the purpose of all this research is finding a superior prediction on colorectal cancer development, evolution and treatment strategies, by incorporating information on genetics with the microbiome, lifestyle, environmental factors to create new risk models.

\section{Dysbiosis - a treatment target of colorectal cancer}

The possibility of modulating the gut microbiome is a new therapeutic strategy in preventing and treating some disorders that are in direct relationship with the microbiota alterations. Considering the possible connection between colorectal cancer and microbiota previously mentioned, there is an increasing interest in discovering microbiomerelated treatments. However, therapy strategies include the use of pre- and probiotics, fecal microbiota transplantation and phage therapy [55].

Fecal microbiota transplantation has been used as a therapeutic method in inflammatory bowel diseases, irritable bowel disease, metabolic syndrome, obesity, atopy, multiple sclerosis, and favorable outcomes. There are no conclusive data from clinical trials in treating colorectal cancer by using fecal microbiota transplant [56].

Another direct strategy is using antibiotics to modulate the microbiome and indirectly influence colorectal cancer evolution, thus targeting some bacteria (Fusobacterium nucleatum, Bacteroides fragilis, Escherichia coli). One study showed that the therapy reduced the amount of Fusobacterium nucleatum and the tumor's overall growth. Still, antibiotics may lead to dysbiosis and drug resistance. Therefore, there is a need for new products targeting bacteria more specifically. For example, a glycopolymer, antagonist of the Escherichia Coli virulence factor FimH, exposed a reduction in bacteria's adherence to the gut epithelia [57]. Furthermore, a low dose of a recombinant BFT-2 enterotoxin, which is a virulence factor of Bacteroides fragilis, reduced the tumor's development in the colorectal cancer mouse model [58]. Another major factor is the interaction between the microbiome and the viral component, and its modulation by phage therapy, due to its role in combating antibiotic-resistant microorganisms [59].

Another promising treatment strategy, affecting the immune response and metabolic pathways, is diet-keeping and vitamin $\mathrm{D}$ administration as an anti-neoplastic effect. [60] It is one of the most significant factors shaping the human microbiome, as studies have shown that alterations induced by deoxycholic acid developed carcinogenesis. At the same time, high dietary fiber and butyrate-producing bacteria may considerably reduce tumor growth [61]. Studies showed that the microbiome might affect the response of 2 cancer immunotherapeutic agents (antiCTLA4 and anti-PD-L1), by amplifying the activation of dendritic and anti-tumor $\mathrm{T}$ cells responses [62-64]. Also, the immunologic stimulation by Bacteroides spp and Bifidobacterium spp affects the efficacy of the therapy. Furthermore, it has been proven that the imbalance of dietary sphingolipids may influence the effectiveness of chemotherapy and radiotherapy [64]. 
Probiotics regulate pathogenic microorganisms and the immune response, which may reduce blood cholesterol, colitis and prevent colorectal cancer, using different mechanisms: releasing detoxifying agents, antiinflammatory factors, anti-carcinogenesis compounds (anti-angiogenesis), short-chain fatty acids that increase the intestinal barrier function [65]. For example, butyrateproducing species such as Clostridium butyricum and Bacillus subtilis may have an anti-tumor effect; Lactobacillus casei (strain BL23) may suppress colorectal cancer by targeting intestinal dysbiosis [66], while Lactobacillus casei (strain ATCC 334) produce ferrochrome which prevents colorectal cancer evolution by apoptosis mediated through the c-Jun $\mathrm{N}$-terminal kinase pathway [67], and Lactobacillus casei (rhamnosus Lcr35) inhibit intestinal mucositis $[68,69]$.

As already mentioned above, the intestinal microbiome, through the stimulation of the immune system, has a natural anti-carcinogenesis effect, so, it has been suggested as a key mechanism of cancer immunotherapy. There are three known ways: microbial antigens activate T-cell response with activating tumorspecific immune response (Bifidobacteria spp, Akkermansia muciniphilia, Bacteroides spp, Enterococcus hirae), the activation of pattern recognition receptors that mediate pro-immune and anti-inflammatory effects and the release of small metabolites that mediate systemic effects in the host (polyamines, vitamin, desaminotyrosine) [70].

All these data show the importance of new treatment strategies in different types of cancer, including colorectal cancer, meaning combined chemo- and immunotherapy with adjuvant therapies aiming the intestinal microbiota, such as diet, pre- and probiotics and vitamin D supplementation [71].

\section{Conclusions}

Despite the implemented screening programs many countries have already adopted, colorectal cancer remains a serious public health issue, being the third leading cause of cancer death. For this reason, research must continue to explore new strategies regarding the prevention, prediction, diagnosis and treatment options. Considering the major roles gut microbiota has on metabolism, nutrition and the immune system, as well as, tumorigenesis induced by DNA alterations due to dysbiosis, further research is expected to discover specific microorganisms and their metabolites connected to colorectal cancer induction and progression. This may provide new tools in the clinical management of colorectal cancer patients.

\section{Conflict of interest disclosure}

There are no known conflicts of interest in the publication of this article. The manuscript was read and approved by all authors.

\section{Compliance with ethical standards}

Any aspect of the work covered in this manuscript has been conducted with the ethical approval of all relevant bodies and that such approvals are acknowledged within the manuscript.

\section{References}

1. Aguiar-Pulido V, Huang W, Suarez-Ulloa V, Cickovski T, Mathee K, Narasimhan G. Metagenomics, Metatranscriptomics, and Metabolomics Approaches for Microbiome Analysis. Evol Bioinform Online. 2016 May 12;12(Suppl 1):5-16. doi: 10.4137/EBO.S36436

2. Ai L, Tian H, Chen Z, Chen H, Xu J, Fang JY. Systematic evaluation of supervised classifiers for fecal microbiota-based prediction of colorectal cancer. Oncotarget. 2017 Feb 7;8(6):9546-9556. doi: 10.18632/oncotarget. 14488

3. Allali I, Delgado S, Marron PI, Astudillo A, Yeh JJ, Ghazal H, Amzazi S, Keku T, Azcarate-Peril MA. Gut microbiome compositional and functional differences between tumor and non-tumor adjacent tissues from cohorts from the US and Spain. Gut Microbes. 2015;6(3):161-72. doi: 10.1080/19490976.2015.1039223

4. Arnold JW, Roach J, Azcarate-Peril MA. Emerging Technologies for Gut Microbiome Research. Trends Microbiol. 2016 Nov;24(11):887-901. doi: 10.1016/j.tim.2016.06.008

5. Farshidfar F, Kopciuk KA, Hilsden R, McGregor SE, Mazurak VC, Buie WD, MacLean A, Vogel HJ, Bathe OF. A quantitative multimodal metabolomic assay for colorectal cancer. BMC Cancer. 2018 Jan 4;18(1):26. doi: $10.1186 / \mathrm{s} 12885-017-3923-\mathrm{z}$

6. Mazilu L, Stanculeanu DL, Gheorghe AD, Voinea F, Suceveanu AP, Suceveanu AI, et al. Incidence of Chemotherapy-Induced Paripheral Neuropathy in Cancer Patients in clinical Practice. Farmacia. 2019; 67(3):472-476. doi: 10.31925/farmacia.2019.3.14

7. Lee V, Le DT. Efficacy of PD-1 blockade in tumors with MMR deficiency. Immunotherapy. 2016;8(1):1-3. doi: 10.2217/imt.15.97

8. Tuta LA, Iorga I, Azis O, Voinea F. End-of-life Care in Elderly Patients with End-Stage Renal Disease - Ethical and Clinical Issues. SGEM 2015, Book 1: Psychology and Psychiatry, Sociology and Healthcare, Education Conference Proceedings, 1, 2015, pp. 487-493.

9. Raskov H, Burcharth J, Pommergaard HC. Linking Gut Microbiota to Colorectal Cancer. J Cancer. 2017 Sep 20;8(17):3378-3395. doi: 10.7150/jca.20497

10. Todoric J, Antonucci L, Karin M. Targeting Inflammation in Cancer Prevention and Therapy. Cancer Prev Res (Phila). 2016 Dec;9(12):895-905. doi: 10.1158/1940-6207.CAPR-16-0209 
11. Lv Y, Ye T, Wang HP, Zhao JY, Chen WJ, Wang X, Shen CX, Wu YB, Cai YK. Suppression of colorectal tumorigenesis by recombinant Bacteroides fragilis enterotoxin-2 in vivo. World J Gastroenterol. 2017 Jan 28;23(4):603-613. doi: 10.3748/wjg.v23.i4.603

12. Suceveanu AI, Mazilu L, Nitipir C, Pantea Stoian A, Parepa I, Voinea C. et al. Diabetes Mellitus raise the risk for Interval Colorectal Cancer and Advanced Adenomas. Revista de chimie (Bucharest). 2019; 70(5): 1808-1811. doi: 10.37358/RC.19.5.7220

13. Brennan CA, Garrett WS. Fusobacterium nucleatum symbiont, opportunist and oncobacterium. Nat Rev Microbiol. 2019;17(3):156-166. doi: 10.1038/s41579018-0129-6

14. Moraru D, Suceveanu AP, Pantea Stoian A, Nitipir C, Pituru S, Voinea F, et al. Amyloidosis - the importance of an early diagnosis. Proceeding of 35 Balkan Medical Week, 25th- 27th September, Athens, Greece pp. 182187. ISBN: 978-88-85813-23-6

15. Tofolean DE, Mazilu L, Stăniceanu F, Mocanu L, Suceveanu AI, Baz RO, Parepa RI, Suceveanu AP, Bondari S, Bondari D, Voinea F. Clinical presentation of a patient with cutis laxa with systemic involvement: a case report. Rom J Morphol Embryol. 2015;56(3): 1205-10.

16. Mazilu L, Suceveanu AI, Tomescu D, Ciufu N, Baz R, Suceveanu AP, Parepa IR, Tofolean DE, Voinea F. Optimizing the indication for breast-conservative surgery (BCS) in patients with locally-advanced breast cancer. Chirurgia (Bucur). 2013 Jul-Aug;108(4):47881.

17. Nakatsu G, Li X, Zhou H, Sheng J, Wong SH, Wu WK, Ng SC, Tsoi H, Dong Y, Zhang N, He Y, Kang Q, Cao L, Wang K, Zhang J, Liang Q, Yu J, Sung JJ. Gut mucosal microbiome across stages of colorectal carcinogenesis. Nat Commun. 2015 Oct 30;6:8727. doi: 10.1038/ncomms9727

18. Suceveanu AI, Mazilu L, Katsiki N, Parepa I, Voinea F, Pantea-Stoian A, Rizzo M, Botea F, Herlea V, Serban D, Suceveanu AP. NLRP3 Inflammasoem Biomerker - Could Be the New Tool for Improved Cardiometabolic Syndrome Outcome. Metabolites. 2020;10:448; doi: 10.3390/metabo10110448

19. Gagnière J, Raisch J, Veziant J, Barnich N, Bonnet R, Buc E, Bringer MA, Pezet D, Bonnet M. Gut microbiota imbalance and colorectal cancer. World $J$ Gastroenterol. 2016 Jan 14;22(2):501-18. doi: 10.3748/wjg.v22.i2.501

20. Kirov KG. A scientometric approach of dynamic science institutionalization in the field of laparoscopic proctocolectomy. J Clin Invest Surg. 2019;4(2):88-95. doi: 10.25083/2559.5555/4.2/88.95

21. Tsilimigras MC, Fodor A, Jobin C. Carcinogenesis and therapeutics: the microbiota perspective. Nat Microbiol. 2017;2:17008. doi: 10.1038/nmicrobiol.2017.8
22. Thaiss CA, Levy M, Korem T, et al. Microbiota Diurnal Rhythmicity Programs Host Transcriptome Oscillations. Cell. 2016;167(6):1495-1510.e12. doi: 10.1016/j.cell.2016.11.003

23. Brănescu C, Serban D, Dascălu AM, Oprescu SM, Savlovschi C. Interleukin 6 and lipopolysaccharide binding protein - markers of inflammation in acute appendicitis. Chirurgia (Bucur). 2013;108(2):206-14.

24. Gur C, Ibrahim Y, Isaacson B, Yamin R, Abed J, Gamliel M, Enk J, Bar-On Y, Stanietsky-Kaynan N, Coppenhagen-Glazer S, Shussman N, Almogy G, Cuapio A, Hofer E, Mevorach D, Tabib A, Ortenberg R, Markel G, Miklić K, Jonjic S, Brennan CA, Garrett WS, Bachrach G, Mandelboim O. Binding of the Fap2 protein of Fusobacterium nucleatum to human inhibitory receptor TIGIT protects tumors from immune cell attack. Immunity. 2015 Feb 17;42(2):344355. doi: 10.1016/j.immuni.2015.01.010

25. Kovatcheva-Datchary P, Nilsson A, Akrami R, Lee YS, De Vadder F, Arora T, Hallen A, Martens E, Björck I, Bäckhed F. Dietary Fiber-Induced Improvement in Glucose Metabolism Is Associated with Increased Abundance of Prevotella. Cell Metab. 2015 Dec 1;22(6):971-82. doi: 10.1016/j.cmet.2015.10.001

26. Frunza TC, Lunca S, Baciu I, et al. LARS-like symptoms in the general population may suggest the significance of postoperative functional problems and emotional implications of rectal surgery. J Mind Med Sci. 2019; 6(2): 278-285. doi: 10.22543/7674.62.P278285

27. Suceveanu AI, Stoian AP, Parepa IR, Voinea C, Hainarosie R, Manuc D, et al. Gut Microbiota Patterns in Obese and Type 2 Diabetes (T2D) Patients from Romanian Black Sea Coast Region. REVISTA DE CHIMIE (Bucharest). 2018;69(8):2260-2267. doi: 10.37358/RC.18.8.6512

28. Suceveanu AI, Manea ME, Mazilu L, Voinea C, Catrinoiu D, et al. Metformin and its benefits in improving gut microbiota disturbances in diabetes patients. In Metformin Monography edited by Anca Pantea Stoian, ISBN: 978-1-83880-428-2 InTech Ed; 2019; pp. 45-60; doi: 10.5772/intechopen.88749

29. Mazilu L, Stanculeanu DL, Gheorghe AD, Suceveanu AP, Parepa I, Voinea F, et al. Metformin and it's implication in cancer therapy (review) Publisher: InTech. Book title: Metformin (ISBN 978-1-83880428-2), pp. 113-126. Published: 27 May 2020.

30. Boulangé CL, Neves AL, Chilloux J, Nicholson JK, Dumas ME. Impact of the gut microbiota on inflammation, obesity, and metabolic disease. Genome Med. 2016 Apr 20;8(1):42. doi: 10.1186/s13073-0160303-2

31. Aarts E, Ederveen THA, Naaijen J, Zwiers MP, Boekhorst J, Timmerman HM, Smeekens SP, Netea MG, Buitelaar JK, Franke B, van Hijum SAFT, Arias 
Vasquez A. Gut microbiome in ADHD and its relation to neural reward anticipation. PLoS One. 2017 Sep 1;12(9):e0183509. doi: 10.1371/journal.pone.0183509

32. Pärtty A, Kalliomäki M, Wacklin P, Salminen S, Isolauri E. A possible link between early probiotic intervention and the risk of neuropsychiatric disorders later in childhood: a randomized trial. Pediatr Res. 2015 Jun;77(6):823-8. doi: 10.1038/pr.2015.51

33. Stevens AJ, Purcell RV, Darling KA, Eggleston MJF, Kennedy MA, Rucklidge JJ. Human gut microbiome changes during a 10 week Randomised Control Trial for micronutrient supplementation in children with attention deficit hyperactivity disorder. Sci Rep. 2019 Jul 12;9(1):10128. doi: 10.1038/s41598-019-46146-3

34. Bao N, Chen F, Dai D. The Regulation of Host Intestinal Microbiota by Polyphenols in the Development and Prevention of Chronic Kidney Disease. Front Immunol. 2020 Jan 8;10:2981. doi: 10.3389/fimmu.2019.02981

35. Tudosie MS, Miulescu RD, Negulescu V, Ionica M, Stefan SD, Corlan, G, Macovei R. Evaluation and modeling of pharmacokinetics of copper ion during hemodialysis. Farmacia. 2013;61(1):55-63.

36. Sarhadi V, Lahti L, Saberi F, Youssef O, Kokkola A, Karla T, Tikkanen M, Rautelin H, Puolakkainen P, Salehi R, Knuutila S. Gut Microbiota and Host Gene Mutations in Colorectal Cancer Patients and Controls of Iranian and Finnish Origin. Anticancer Res. 2020 Mar;40(3):1325-1334. doi: 10.21873/anticanres

37. Pantea-Stoian A, Pituru SM, Hainarosie R, et al. Testosterone therapy, new opportunities in diabetes mellitus. Farmacia. 2018;66(1):1-7.

38. Lee DW, Han SW, Kang JK, Bae JM, Kim HP, Won JK, Jeong SY, Park KJ, Kang GH, Kim TY. Association Between Fusobacterium nucleatum, Pathway Mutation, and Patient Prognosis in Colorectal Cancer. Ann Surg Oncol. 2018 Oct;25(11):3389-3395. doi: 10.1245/s10434-018-6681-5

39. Şavlovschi C, Comandaşu M, Şerban D. Specifics of diagnosis and treatment in synchronous colorectal cancers (SCC). Chirurgia (Bucur). 2013 JanFeb;108(1):43-5.

40. Alius C, Tudor C, Badiu CD, Dascalu AM, Smarandache CG, Sabau AD, Tanasescu C, Balasescu SA, Serban D. Indocyanine Green-Enhanced Colorectal Surgery-between Being Superfluous and Being a Game-Changer. Diagnostics (Basel). 2020 Sep 24;10(10):742. doi: 10.3390/diagnostics10100742

41. Savlovschi C, Serban D, Trotea T, Borcan R, Dumitrescu D. Post-surgery morbidity and mortality in colorectal cancer in elderly subjects. Chirurgia (Bucur). 2013 Mar-Apr;108(2):177-9.

42. Moskal A, Freisling H, Byrnes G, et al. Main nutrient patterns and colorectal cancer risk in the European
Prospective Investigation into Cancer and Nutrition study. Br J Cancer. 2016 Nov 22;115(11):1430-1440. doi: 10.1038/bjc.2016.334

43. Carethers JM, Jung BH. Genetics and Genetic Biomarkers in Sporadic Colorectal Cancer. Gastroenterology. 2015 Oct;149(5):1177-1190.e3. doi: 10.1053/j.gastro.2015.06.047

44. Flemer B, Lynch DB, Brown JM, Jeffery IB, Ryan FJ, Claesson MJ, O'Riordain M, Shanahan F, O'Toole PW. Tumour-associated and non-tumour-associated microbiota in colorectal cancer. Gut. 2017 Apr;66(4):633-643. doi: 10.1136/gutjnl-2015-309595

45. Gao R, Kong C, Huang L, Li H, Qu X, Liu Z, Lan P, Wang J, Qin H. Mucosa-associated microbiota signature in colorectal cancer. Eur J Clin Microbiol Infect Dis. 2017 Nov;36(11):2073-2083. doi: 10.1007/s10096-017-3026-4

46. Laamiri G, Ghalleb M, Ammar NB, Zribi S, Mighri M, Bouassida M, Touinsi $\mathrm{H}$. Bowel obstruction due to the tightening of a loose bowel adhesion with uterus enlargement during pregnancy. J Clin Invest Surg. 2020; 5(2):109-112. doi: 10.25083/2559.5555/5.2/109.112

47. Gao Z, Guo B, Gao R, Zhu Q, Qin H. Microbiota disbiosis is associated with colorectal cancer. Front Microbiol. 2015;6:20. doi: 10.3389/fmicb.2015.00020

48. Shang FM, Liu HL. Fusobacterium nucleatum and colorectal cancer: A review. World J Gastrointest Oncol. 2018;10(3):71-81. doi: 10.4251/wjgo.v10.i3.71

49. Zhang X, Zhu X, Cao Y, Fang JY, Hong J, Chen H. Fecal Fusobacterium nucleatum for the diagnosis of colorectal tumor: A systematic review and metaanalysis. Cancer Med. 2019 Feb;8(2):480-491. doi: 10.1002/cam4.1850

50. Navarro M, Nicolas A, Ferrandez A, Lanas A. Colorectal cancer population screening programs worldwide in 2016: An update. World J Gastroenterol. 2017;23(20):3632-3642. doi: 10.3748/wjg.v23.i20.3632

51. Puca BM, Braila AD, Obleaga CV, Braila M, Saad H, Lungulescu C, Deca M. Conservative surgical treatment in cervical dysplastic lesions associated with cystorectocele. J Mind Med Sci. 2019;6(2):340-345. doi: 10.22543/7674.62.P340345

52. Coghlin C, Murray GI. Biomarkers of colorectal cancer: recent advances and future challenges. Proteomics Clin Appl. 2015 Feb;9(1-2):64-71. doi: 10.1002/prca.201400082

53. Yu J, Feng Q, Wong SH, et al. Metagenomic analysis of faecal microbiome as a tool towards targeted noninvasive biomarkers for colorectal cancer. Gut. 2017 Jan;66(1):70-78. doi: 10.1136/gutjnl-2015-309800

54. Shah MS, DeSantis TZ, Weinmaier T, McMurdie PJ, Cope JL, Altrichter A, Yamal JM, Hollister EB. Leveraging sequence-based faecal microbial community survey data to identify a composite 
biomarker for colorectal cancer. Gut. 2018 May;67(5):882-891. doi: 10.1136/gutjnl-2016-313189

55. Juul FE, Garborg K, Bretthauer M, Skudal H, Øines MN, Wiig H, Rose Ø, Seip B, Lamont JT, Midtvedt T, Valeur J, Kalager M, Holme Ø, Helsingen L, Løberg M, Adami HO. Fecal Microbiota Transplantation for Primary Clostridium difficile Infection. $N$ Engl J Med. 2018;378(26):2535-2536. doi: 10.1056/NEJMc1803103

56. Filip M, Tzaneva V, Dumitrascu DL. Fecal transplantation: digestive and extradigestive clinical applications. Clujul Med. 2018 Jul;91(3):259-265. doi: 10.15386/cjmed-946

57. Khan AA, Khan Z, Malik A, Kalam MA, Cash P, Ashraf MT, Alshamsan A. Colorectal cancerinflammatory bowel disease nexus and felony of Escherichia coli. Life Sci. 2017 Jul 1;180:60-67. doi: 10.1016/j.lfs.2017.05.016

58. Lv Y, Ye T, Wang HP, Zhao JY, Chen WJ, Wang X, Shen CX, Wu YB, Cai YK. Suppression of colorectal tumorigenesis by recombinant Bacteroides fragilis enterotoxin-2 in vivo. World J Gastroenterol. 2017 Jan 28;23(4):603-613. doi: 10.3748/wjg.v23.i4.603

59. Mirzaei MK, Maurice CF. Ménage à trois in the human gut: interactions between host, bacteria and phages. Nat Rev Microbiol. 2017 Jul;15(7):397-408. doi: 10.1038/nrmicro.2017.30

60. Stoian AP, Mitrofan G, Colceag F, et al. Oxidative Stress in Diabetes A model of complex thinking applied in medicine. Revista de Chimie. 2018;69(9):2515-2519. doi: 10.37358/RC.18.9.6566

61. Cao H, Xu M, Dong W, Deng B, Wang S, Zhang Y, Wang S, Luo S, Wang W, Qi Y, Gao J, Cao X, Yan F, Wang B. Secondary bile acid-induced dysbiosis promotes intestinal carcinogenesis. Int J Cancer. 2017 Jun 1;140(11):2545-2556. doi: 10.1002/ijc.30643

62. West NR, Powrie F. Immunotherapy Not Working? Check Your Microbiota. Cancer Cell. 2015 Dec 14;28(6):687-689. doi: 10.1016/j.ccell.2015.11.010

63. Chirca A, Costea RV, Furtunescu FL, Minca DG. Colorectal cancer: a small review of current and future molecular screening markers and the first steps to personalized medicine. Medical-surgical journalrevista medico-chirurgicala. 2017;121(2):395-402.

64. Camp ER, Patterson LD, Kester M, Voelkel-Johnson C. Therapeutic implications of bioactive sphingolipids: A focus on colorectal cancer. Cancer Biol Ther. 2017; 18(9):640-650. doi: 10.1080/15384047.2017.1345396

65. Lin C, Cai X, Zhang J, Wang W, Sheng Q, Hua H, Zhou X. Role of Gut Microbiota in the Development and Treatment of Colorectal Cancer. Digestion. 2019;100(1):72-78. doi: 10.1159/000494052

66. Motofei IG. Biology of Cancer; From Cellular Cancerogenesis to Supracellular Evolution of Malignant Phenotype. Cancer Invest. 2018;36(5):309317. doi: 10.1080/07357907.2018.1477955

67. Konishi H, Fujiya M, Tanaka H, Ueno N, Moriichi K, Sasajima J, Ikuta K, Akutsu H, Tanabe H, Kohgo Y. Probiotic-derived ferrichrome inhibits colon cancer progression via JNK-mediated apoptosis. Nat Commun. 2016;7:12365. doi: 10.1038/ncomms12365

68. Gradisteanu GP, Stoica RA, Petcu L, et al. Microbiota signatures in type-2 diabetic patients with chronic kidney disease - A Pilot Study. J Mind Med Sci. 2019; 6(1):130-136. doi: 10.22543/7674.61.P130136

69. Chang CW, Liu CY, Lee HC, Huang YH, Li LH, Chiau JC, Wang TE, Chu CH, Shih SC, Tsai TH, Chen YJ. Lactobacillus casei Variety rhamnosus Probiotic Preventively Attenuates 5-Fluorouracil/OxaliplatinInduced Intestinal Injury in a Syngeneic Colorectal Cancer Model. Front Microbiol. 2018 May 15;9:983. doi: 10.3389/fmicb.2018.00983

70. Tulin A, Slavu I, Tulin R, et al. Does sex of the patient play a role in survival for MSI colorectal cancer? J Mind Med Sci. 2018;5(1): 101-108. doi: 10.22543/7674.51.P101108

71. Ding C, Tang W, Fan X, Wu G. Intestinal microbiota: a novel perspective in colorectal cancer biotherapeutics. Onco Targets Ther. 2018 Aug 13;11: 4797-4810. doi: 10.2147/OTT.S170626 